\title{
The ability of second graders to identify solids in different positions and to justify their answer
}

\author{
Authors: \\ Yael Sarfaty ${ }^{1}$ \\ Dorit Patkin \\ Affiliations: \\ ${ }^{1}$ Kibbutzim College of \\ Education, Tel Aviv, Israel \\ Correspondence to: \\ Yael Sarfaty \\ Email: \\ yael_sar@bezeqint.net \\ Postal address: \\ Kibbutzim College of \\ Education, Faculty of \\ Mathematics, 149 Namir \\ Road, Tel Aviv, Israel \\ Dates: \\ Received: 17 Jan. 2013 \\ Accepted: 04 May 2013 \\ Published: 28 June 2013 \\ How to cite this article: \\ Sarfaty, Y., \& Patkin, D. \\ (2013). The ability of second \\ graders to identify solids \\ in different positions and \\ to justify their answer. \\ Pythagoras, 34(1), Art. \#212 \\ 10 pages. http://dx.doi. \\ org/10.4102/pythagoras. \\ v34i1.212

\section{Copyright:} \\ (C) 2013. The Authors. \\ Licensee: AOSIS \\ OpenJournals. This work \\ is licensed under the \\ Creative Commons \\ Attribution License.
}

Read online:

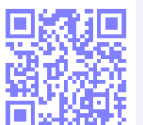

Scan this QR code with your smart phone or mobile device to read online.
From a young age children feel the need to identify two-dimensional geometric figures (shapes) and three-dimensional geometric figures (solids). The National Council of Teachers of Mathematics indicates the importance of being able to identify and name various geometric figures by kindergarten age. One of the objectives of this study was to learn the ability of second graders to identify examples and non-examples of three generally known solids: cylinder, cone and pyramid, and to justify their identification based on the attributes (critical and non-critical) of those solids. Another objective was to find out whether changing the position of the solids would result in those children maintaining their decisions regarding the name or changing their identification of the solids, giving arguments accordingly. Findings of this study illustrate that children can identify and characterise solids presented to them in a typical position. However, they find it difficult to correctly identify the same solids in another position. An interesting finding was that most of the arguments given to justify their identification were based on the specific attributes of the solid rather than on the perception of the solids in general. Findings of the present study suggest that it is highly important for learners to be acquainted with a variety of both non-examples and examples of solids. Moreover, it is recommended that solids are presented to learners not only in the typical position, in order to improve their ability to identify them and understand that the name of the figure does not change when its position changes.

\section{Theoretical background}

Identification and naming of geometric figures are performed from an early age. Children are exposed to geometric figures long before they begin their formal schooling. The National Council of Teachers of Mathematics (NCTM) (2000) explicitly specifies that teaching programmes of this subject should begin at kindergarten age, thus enabling children 'to analyse characteristics and properties of two-dimensional and three-dimensional geometric figures and develop mathematical arguments about geometric relation' (p. 96). During their first years at school, young learners are expected to:

- 'Recognise, name, build, draw, compare and sort two- and three-dimensional shapes;

- Describe attributes and parts of two- and three-dimensional shapes'. (p. 96)

The Mathematics curriculum for kindergarten in Israel (Ministry of Education, 2010) includes the subject of three-dimensional figures or, as it is referred to in the curriculum, solids. Pursuant to the curriculum children will learn:

- 'To identify and name solids. Solids to be named are: cube, cylinder, ball, pyramid, cone, box, prism.

- To identify shapes (identifying the faces) of which the solids are built'. (p. 44)

Later on, in the Mathematics curriculum for primary school, the subject of solids appears in the second grade (Ministry of Education, 2006). According to the curriculum, children will learn about:

- 'Solids: cube, box, cylinder, pyramid, cone, ball - initial acquaintance;

- Identification and naming of solids (in simple cases);

- Observing solids and describing them, including counting of faces, edges and vertices'. (p. 48)

\section{The Van Hiele theory}

According to the geometric thinking model conceived by Van Hiele (1997, 1999), children's geometric thinking is developed in a hierarchical way, from visualisation (or recognition), to analysis (or description), to informal deduction (or ordering), and finally to formal deduction and rigour (or axiomatic approach). According to Van Hiele's theory, partial mastery of a certain level is required though insufficient for mastering a higher level. 
The Van Hiele theory originally related to plane geometry only. Some studies have recently applied the theory of plane geometry to other branches of mathematics, such as solid geometry (Gutiérrez, 1992; Patkin, 2010; Patkin \& Sarfaty, 2012) and arithmetic (Crowley, 1987; Guberman, 2008).

As this study engages in the geometric knowledge of young children, we focus on only the first two levels, that is, visualisation and analysis.

On the first level - visualisation - learners become acquainted with different geometric figures, distinguish between them but are unable to identify and specify the components and attributes of these figures. They name a figure based on its appearance and can describe it by its similarity to a figure that is familiar to them. There is reference to the geometric figure in its entirety. Koester (2003) describes an example of a child who determines that a certain shape is a rectangle because 'it looks like a box' (p. 436). The child's explanation is wrong: he confuses a two-dimensional concept (rectangle) with a three-dimensional concept (box).

On the second level of the Van Hiele model - analysis learners can describe or analyse a geometric figure based on its features and characteristics. They recognise the figure by its attributes. Clements and Sarama (2000) present the case of a child who identifies a certain shape as a rectangle because 'it has two pairs of equal sides and all right angles' (p. 482).

On the other two levels (which are not relevant to this study) learners develop higher levels of geometric thinking.

\section{Critical attributes and non-critical attributes}

In geometry, arguments for determining names of geometric figures can be divided into two types. The first type relates to the critical attributes of the concept and the second relates to the non-critical attributes of the concept. Tall and Vinner (1981) distinguish between the terms 'concept image' and 'concept definition'. The term concept image is used in order to describe the total cognitive structure relevant to the concept, including all the mental pictures, associated properties and processes. It is built up over the years through experiences of all kinds, changing as the individual encounters new stimuli and matures. Concept definition is a formulation of words used to specify a concept. It may be learnt by an individual by memorisation or more meaningfully learnt and related to a greater or lesser degree to the concept as a whole. Critical attributes must be present in every example of the concept and are derived from the concept definition (Hershkowitz, 1989, 1990). An example of a critical attribute of a solid: 'This is a triangular pyramid because all its faces are shaped like a triangle.' Non-critical attributes are found only in a subset of the concept examples. An example of a non-critical attribute: 'This is a pyramid because it has a square-shaped basis.' This is not a critical attribute because the pyramid basis can be any polygon and this attribute is not critical for determining that a solid is indeed a pyramid.
Burger and Shaughnessy (1986) argue that non-critical attributes embody an element of visual argument. One of the objectives of mathematics education is to induce children to use only critical attributes as reasoning when identifying examples and building mathematical concepts. Those who base their arguments on critical attributes function on Van Hiele's second level.

\section{Examples and non-examples}

When building knowledge and concepts it is extremely important to present children with examples and, at the same time, non-examples in order to facilitate concept formation in a swifter and fuller way (Klausmeier \& Feldman, 1975; McKinney, Larkins, Ford \& Davis, 1983). In mathematics education, the use of examples and non-examples has been intensively studied in the context of geometric concept acquisition (Cohen \& Carpenter, 1980; Petty \& Jansson, 1987; Vinner, 1991; Wilson, 1986). One of the conclusions is that the use of non-examples constitutes part of the formation and creation of a concept (Tsamir, Tirosh \& Levenson, 2008). According to Clements and Sarama (2000), good and relevant non-examples, which can enhance the ability to identify and name geometric figures, encompass only part of the critical attributes but not all of the required critical attributes. The use of these can help learners to correctly consolidate the learnt concept. Figure 1 presents an example and a nonexample of a cylinder.

\section{Prototype and non-prototype}

The fact that there is an example or several examples that constitute a prototype is another important component of which we have to be aware when presenting examples. Hershkowitz (1989) claims that all the examples that have common specific visual characteristics become prototypes. According to Tsamir et al. (2008), a prototypical example is intuitively accepted as representative of the concept. That is, it is accepted immediately with certainty and without feeling that any kind of justification is required. Figure 2 presents an example of a prototype cylinder, in which the altitude is longer than the diameter of the cylinder base, and a nonprototype cylinder, in which the diameter of the cylinder base is longer than the altitude.

Every geometric concept has at least one prototype example, which is the first to be acquired intuitively when learning a

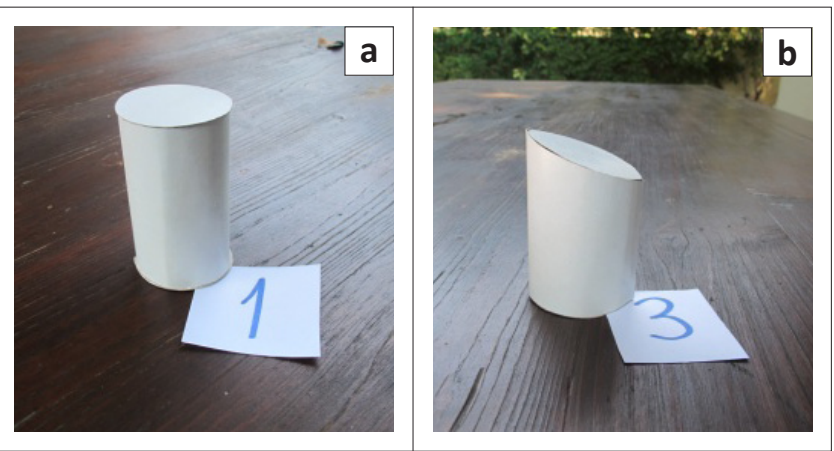

FIGURE 1: An example (a) and a non-example (b) of a cylinder. 
concept. The prototype plays an important role in the concept formation. Hershkowitz (1989) maintains that, in addition to the required and sufficient attributes that are common to all the examples of that concept, examples that are a prototype of a shape have also special (non-critical) attributes 'dominating and attracting our attention' (p. 73). An example becomes a prototype due to its strong visual features. Conversely, the other examples are rejected because they lack those special visual attributes of the prototype example (Hershkowitz, 1992).

When distinguishing between examples and non-examples of shapes, one can see that the prototype is the basis of prototypical judgement. That is, the prototype example is a reference framework against which learners judge the other examples instead of using the concept definition, that is, its attributes (Hershkowitz, 1992). In such cases, learners stick to the prototype example which entails applying noncritical attributes to the rest of concept examples. As a result, learners who fail to identify a certain concept example make wrong decisions and do not consider it as one of the concept examples (Hershkowitz \& Vinner, 1983). Watson and Mason (2005) argue that learners are familiar with a small variety of examples only.

\section{Typical position and non-typical position}

When presenting geometric figures, one should pay attention also to the position of the figure. There are two kind of positions: a 'typical position' and an 'atypical position'. In a typical position, the solid 'stands' on its basis. In an atypical position, the solid is 'lying-on-its side', for example, on the lateral surface of a cone or cylinder or on one of the faces of a pyramid's lateral surface.

Tirosh, Tsamir, Levenson, Tabach and Barkai (2011) conducted a study that investigated pre-service and inservice teachers' knowledge of two-dimensional and threedimensional figures. The researchers presented examples of geometric figures in typical and atypical positions.

Burger and Shaughnessy (1986) describe the direction or position of a geometric figure as a non-critical and irrelevant attribute. According to Tirosh, Tsamir and Levenson (2010), studies show that children tend to treat non-critical attributes, such as the shape's position (horizontal basis) or size (wide or narrow), as critical attributes. Figure 3 presents an example of a cylinder in a typical and an atypical position.

Prototype figures are always depicted in typical position. In order to avoid adhering to one prototype example in a typical position, it is recommended that children be exposed to a large number of examples that represent a specific concept, as well as to many non-examples of the same concept in different positions. This will allow the learners to achieve a consolidated concept (NCTM, 2000).

This study focuses on the ability of second grade children to identify solids in different positions and to justify their answers.

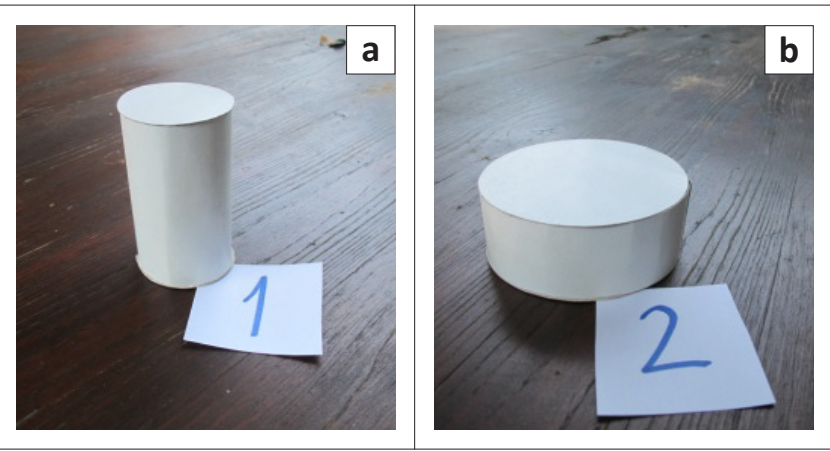

FIGURE 2: A prototype cylinder (a) and a non-prototype cylinder (b).

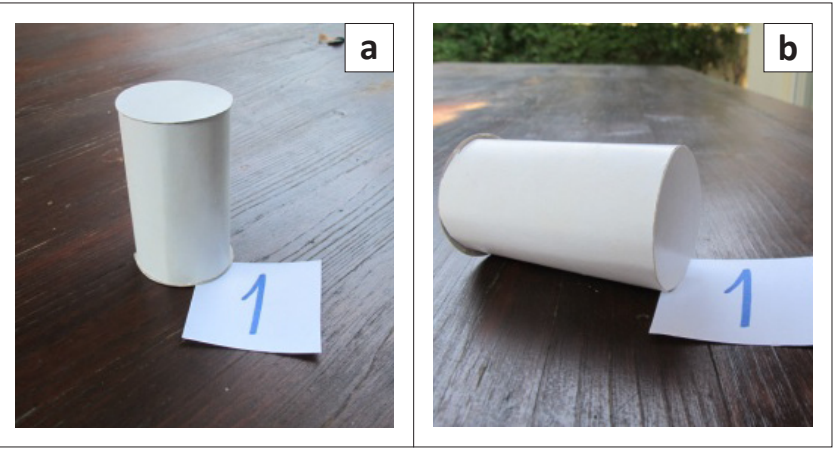

FIGURE 3: An example of a cylinder in a typical position (a) and an atypical position (b).

\section{Methodology Research objectives}

The first objective of this study was to learn second graders' ability to:

- identify examples and non-examples of three types of solids, cylinder, cone and pyramid, in a typical position

- justify their identification based on the attributes (critical and non-critical) of those solids.

The second objective of this study was to find out whether the children maintain or change their identification of the solids, giving arguments accordingly, when the position of the examples is changed.

\section{Research population}

The research population consisted of 35 children from the second grade at a school located at the centre of Israel. Until the study, the children had not formally studied the subject of solids at school. It is important to note that these children were supposed to have learnt to identify and name solids such as cones, cylinders and pyramids in kindergarten, according to Israel's kindergarten Mathematics curriculum (Ministry of Education, 2010).

\section{Research tools}

The research tools included 14 physical solids (Appendix 1) and a structured interview.

\section{The physical solids (Appendix 1)}

Fourteen physical solids were shown to the children: eight solids with mathematical names, namely two cylinders (solid 1 , 
a 'tall' cylinder, and solid 2, a 'flat' cylinder); two cones (solid 6, a 'clown hat' cone, and solid 7, a 'Chinese hat' cone); four pyramids (solid 9, a triangular pyramid, solid 10, a square pyramid, solid 11, a quadrilateral concave pyramid, and solid 14, a hexagonal pyramid). Of these eight solids, five are clear prototypes (solids 1, 6, 7, 8 and 9) and three are perceived to a lesser extent to be prototypes (solids 2, 11 and 14).

The remaining six solids are non-examples of those solids: solid 3 and solid 4 are non-examples of a cylinder, solid 5 is a non-example of a cone and solids 10,12 and 13 are nonexamples of a pyramid.

\section{The structured interview}

The structured interview comprised 28 questions, two questions for each of the 14 physical solids. The first question related to the typical position of each solid (position A) and the second question related to the solid's position after it had been changed, usually to a 'lying' position (position B). In every question children were asked to justify their answer.

For example, the researcher showed the learner solid 1 in position A, and asked the learner, 'Is this a cylinder? Please explain why.' Then, the researcher changed the position of solid 1 to position B and asked the learner, 'Is this a cylinder? Please explain why.'

\section{Research procedure}

During an individual meeting with every child, the 14 physical solids were presented by the researcher in two positions: a typical position (position A) and an atypical position (position B). The order of presentation of the solids was identical for every child. As mentioned previously, each child was asked to confirm or refute the name given by the researcher and then explain and justify their answer. The reasoning behind the identification of the solids was examined through the explanations. Each interview lasted $30 \mathrm{~min}-40 \mathrm{~min}$.

\section{Research method and analysis method}

The outcomes of the interview questions relevant to the identification of the solids were quantitatively analysed (frequencies of correct and incorrect responses). A qualitative content analysis was used for the arguments that were given by the learners as justification for their answers. All the arguments were classified into categories by the two researchers. No differences were found between their judgements of the arguments.

\section{Ethical considerations}

Permission to conduct the study was granted by the principal of the school, the teachers and the parents of the participating children. The methods, aims and objectives of the study were explained and discussed with all of them. The aims were explained to the participating children and they agreed to take part in the study. The name of the college and those of the children will not be divulged in this article.

\section{Findings The first research objective}

The first research objective was to learn the children's ability to identify examples and non-examples of a cylinder, a cone and a pyramid in typical positions, giving reasons.

Table 1 indicates the frequency of correct and incorrect answers and presents the percentage of children who did not answer the questions.

Table 1 illustrates that the percentage of children correctly identifying solids with a known mathematical name (cylinder, cone and pyramid) in typical position (position A) ranged between $42.9 \%$ and $100 \%$. Over $80 \%$ of the children correctly identified the solids known to them, that is, to which they are exposed in their day-to-day life: the prototypes (solids 1, 6, 7, 8 and 9). All of the children (100\%) correctly identified solid 1 (the cylinder). The percentage of correct answers to the two cones (solid 6 and solid 7) was also high: 91.4\% and 85.7\%, respectively. As for the pyramids (solid 8 and solid 9), the correct answers ranged between $88.6 \%$ and $80 \%$ respectively.

The lowest percentage of correct answers related to solids that have a known mathematical name (cylinder, cone and pyramid), but have a lower exposure in everyday life. For example, solid 2, the 'flattened' cylinder whose altitude is shorter than its diameter $(65.7 \%)$, solid 14 , the hexagonal pyramid $(42.9 \%)$, and solid 11, the quadrilateral concave pyramid (11.4\%).

As for the non-example solids, the correct answers ranged between $42.9 \%$ and $82.9 \%$. The percentage of correct identification of non-examples of a cylinder (solid 3) was the lowest (42.9\%) and that of non-examples of a pyramid (solid 12) was the highest $(82.9 \%)$.

The answers were accompanied by arguments, 306 in total. As already mentioned, all of the children were asked to justify their answers but not all of them did so. Nevertheless,

TABLE 1: Frequency (\%) of identifying examples and non-examples of solids (in position A).

\begin{tabular}{llccc}
\hline $\begin{array}{l}\text { Name of } \\
\text { solid }\end{array}$ & Solid ( $\mathbf{N}$ 35) & $\begin{array}{c}\text { Correct } \\
(\mathbf{\%})\end{array}$ & $\begin{array}{c}\text { Incorrect } \\
(\mathbf{\%})\end{array}$ & $\begin{array}{c}\text { Did not } \\
\text { answer (\%) }\end{array}$ \\
\hline Cylinder & Solid 1 - Cylinder ('tall') & 100 & 0 & 0 \\
& Solid 2 - Cylinder ('flat') & 65.7 & 34.3 & 0 \\
& Solid 3 - Non-example of a cylinder & 42.9 & 57.1 & 0 \\
& Solid 4 - Non-example of a cylinder & 48.6 & 51.4 & 0 \\
Cone & Solid 5 - Non-example of a cone & 71.4 & 28.6 & 0 \\
& Solid 6 - Cone ('clown hat') & 91.4 & 0 & 8.6 \\
& Solid 7 - Cone ('Chinese hat') & 85.7 & 5.7 & 8.6 \\
Pyramid & Solid 8 - Triangular pyramid & 88.6 & 11.4 & 0 \\
& Solid 9 - Square pyramid & 80 & 20 & 0 \\
& Solid 10 - Non-example of a pyramid & 57.1 & 42.9 & 0 \\
& Solid 11 - Quadrilateral concave & 11.4 & 88.6 & 0 \\
& pyramid & & & \\
& Solid 12 - Non-example of a pyramid & 82.9 & 17.1 & 0 \\
& Solid 13 - Non-example of a pyramid & 80 & 20 & 0 \\
& Solid 14 - Hexagonal pyramid & 42.9 & 57.1 & 0 \\
\hline
\end{tabular}

$N$, number. 
it is noteworthy that none of the children gave more than one argument per answer and none gave no answer at all. All of the arguments for determining the answer were classified according to two categories: arguments based on perception of the solid in general (visualisation, first level according to Van Hiele theory) (category 1); and arguments based on the attributes of the solid (analysis, second level according to Van Hiele theory) with reference to and distinction between critical and non-critical attributes (category 2).

\section{Category 1: Arguments based on perception of the solid in general}

Only 28 arguments (about 9\%) were based on general perception of the solid. Examples of these are:

- 'Because it has the shape of a toilet paper roll'.

- 'Because it has the shape of a cone'.

- 'Because it looks like an ice-cream cone'.

- 'Because it's like a boat with a prow'.

- 'Because it looks like a clown's hat'.

- 'Because it is like the pyramids in Egypt - it is pretty both on the inside and the outside'.

- 'Because it's like a circus tent'.

\section{Category 2: Arguments based on the attributes of the solid}

The other 276 arguments (about 91\%) were based on the attributes of the solids. Many arguments were given whilst touching and demonstrating the existence of that attribute in the solid. For example, they described the attribute of the curved surface of the cylinder while rolling the solid.

As mentioned above in the theoretical background, the arguments based on attributes can be divided into two types: those based on critical attributes (195 out of 276) and those based on non-critical attributes (81 out of 276).

Examples of arguments based on critical attributes of the solid:

- 'This is a cylinder because it is round and has no vertices'.

- 'This is a cone because it is rounded at the bottom and pointed at the top'.

- 'This is a pyramid because it has pointed parts and some triangular parts'.

Examples of arguments based on non-critical attributes of the solid:

- 'This is a cylinder because it is long' (solid 1) ... 'and this is not a cylinder because it is not tall and it resembles a drum' (solid 2) - this non-critical attribute relates to the cylinder altitude.

- 'Because there are seven vertices so it cannot be a pyramid' (argument given for failing to identity solid 14 as a hexagonal pyramid) - a non-critical attribute relating to the number of vertices of the polygon which forms the pyramid basis.

- 'Because there is a square here and if it was a pyramid we would have a triangle' (while indicating the basis of the square pyramid, solid 9) - a non-critical attribute relating to the polygon that forms the pyramid basis.
- 'Because at the bottom there is no triangle' (whilst indicating the basis of the hexagonal pyramid) - a noncritical attribute relating to the polygon that forms the pyramid basis.

\section{The second research objective}

The second research objective was to find out whether a change in the position of the examples of the three types of solids (cylinder, cone and pyramid - solids 1, 2, 6, 7, 8, 9, 11 and 14) would result in a change in the children's decisions regarding the name (transition from position $\mathrm{A}$ to position $\mathrm{B}$ ), with relevant justification.

Table 2 illustrates that the number of correct identifications of solids cylinders, cones and pyramids in position $\mathrm{B}$ ranges between $11.4 \%$ and $85.7 \%$.

Of the five more familiar solids (solids 1, 6, 7, 8 and 9), 80\% of the children correctly identified two of them in position $B$ (solid 1, the prototype cylinder, and solid 8, the triangular pyramid). On the other hand, in position $\mathrm{A}$, over $80 \%$ of the children correctly identified all five.

The greatest difference between position $\mathrm{A}$ and position $\mathrm{B}$ was demonstrated in solid 6 , the cone $(91.4 \%$ in position A and $71.4 \%$ in position $B$ ), and in solid 9 , the square pyramid ( $80 \%$ in position $A$ and $40 \%$ in position $B$ ).

In the case of the three less familiar solids: solid 2, the 'flattened' cylinder showed no difference between the two positions (65.7\%); only $8.6 \%$ of the children identified solid 11, the quadrilateral concave pyramid, in position B; and only $11.4 \%$ of the children identified solid 14, the hexagonal pyramid, in position B.

The answers given to solids in position $\mathrm{B}$ were also accompanied by arguments, 108 in total. Most of the arguments ( 73 out of 108 ) were given in connection with those

TABLE 2: Frequency (\%) of identifying solids in position A versus position B.

\begin{tabular}{llcccc}
\hline $\begin{array}{l}\text { Name of } \\
\text { solid }\end{array}$ & Solid $(\boldsymbol{N}=\mathbf{3 5})$ & Position & $\begin{array}{c}\text { Correct } \\
(\mathbf{\%})\end{array}$ & $\begin{array}{c}\text { Incorrect } \\
(\mathbf{\%})\end{array}$ & $\begin{array}{c}\text { Did not } \\
\text { answer (\%) }\end{array}$ \\
\hline Cylinder & Solid 1 - Cylinder & A & 100 & 0 & 0 \\
& Solid 2 - Cylinder & B & 85.7 & 14.3 & 0 \\
Cone & Solid 6 - Cone & B & 65.7 & 34.3 & 0 \\
& & A & 95.7 & 34.3 & 0 \\
& Solid 7 - Cone & B & 71.4 & 0 & 8.6 \\
& & A & 85.7 & 5.7 & 8.6 \\
Pyramid & Solid 8 - Triangular & B & 71.4 & 28.6 & 0 \\
& pyramid & A & 88.6 & 11.4 & 0 \\
& Solid 9 - Square & B & 85.7 & 14.3 & 0 \\
& pyramid & A & 80.0 & 20 & 0 \\
& Solid 11 - Quadrilateral & B & 40.0 & 60 & 0 \\
& concaved & A & 11.4 & 88.6 & 0 \\
& pyramid & B & 8.6 & 91.4 & 0 \\
\hline & Solid 14 - Hexagonal & A & 42.9 & 57.1 & 0 \\
& pyramid & B & 11.4 & 88.6 & 0 \\
\hline
\end{tabular}

$N$, number. 
solids whose name, according to the children's identification, did not change, namely the solids that kept their name after changing position.

Below are some examples of justifications for keeping the name of the solid after changing the position.

Thirty-four arguments related to cylinders. For example:

- 'The same but reversed'.

- 'They have a fixed shape'.

- 'Still a cylinder'.

- 'Because it does not matter how we position it'.

- 'It remains a cylinder any way we turn it'.

Twelve arguments related to cones. For example:

- 'The same but lying on its side'.

- 'Because it rolls like a cone'.

- 'It's still a cone regardless of how it looks'.

Twenty-seven arguments related to pyramids. For example:

- 'This is always a pyramid because no matter what, it always has a pointed tip' (regarding the triangular pyramid).

- 'Regardless of how we rotate it'.

- 'Because it is still the same shape; we have only turned it'.

- 'One can put it in any way; it still remains a pyramid'.

- 'Because it still has pointed tips at the end of every line'.

Below are some examples of justifications for not keeping the name of the solid after changing the position.

Three arguments related to cylinders. For example:

- 'A cylinder should stand upright, not lying on its side'.

- 'Since it is lying on its side then it is not a cylinder'.

Twelve arguments related to cones. For example:

- 'Because only when it is upright it is a cone'.

- 'Because a cone is upright and needs a pointed top'.

- 'Because it is lying on its side and it is short'.

Twenty arguments related to pyramids. For example:

- 'Because now it has two pointed tips and a pyramid needs only one' (when we laid the square pyramid on its side).

- 'Because it is (indicating the basis, the square) too flat' (the square pyramid).

- 'Because in a pyramid we have to see the triangles and here we see a square' (the square pyramid).

- 'Because now it does not have the shape of a pyramid. There is a line above' (the square pyramid).

- 'Because it is lying on the side (indicating the hexagonal) and this is not a triangle' (the hexagonal pyramid).

To sum up, the children who identified the solid in position $\mathrm{B}$ as the same solid in position A specified again in their justifications that the solid did not change and gave the same attributes of the solid for position B as well. The reasons children gave when identifying the solid in position B as not the same solid stemmed from the change from the typical position to an atypical position.

\section{Discussion and conclusions}

The ability to identify, characterise and name geometric shapes is one of the skills to be developed in young learners in order to promote their mastery of the first and second geometric thinking levels. In this study we investigate second graders' ability to identify three-dimensional figures (solids) in different positions and to justify their answers.

Findings show that more than $80 \%$ of the children correctly identify prototype cylinders, cones and pyramids in typical positions. A lower percentage was obtained in the identification of non-prototype cylinders, cones and pyramids. This was especially noticeable for those identifying the two cylinders (solid 1 and solid 2). The difference in the percentage of children who correctly named these two cylinder types in position A (100\% vs. $65.7 \%)$ is due to the misconception that a cylinder altitude should be longer than the diameter of the cylinder base. It is to be assumed that the children who made an incorrect identification, turned a noncritical attribute, altitude, into a critical attribute following their exposure to the cylinder prototype, which is tall and 'narrow'. This brought about a prototypical judgement followed by an incorrect decision (34.3\%) not to include solid 2 as an example of cylinder. This is corroborated by the findings of Vinner and Hershkowitz (1983).

Over $50 \%$ of the children failed to identify the hexagonal pyramid (solid 14) in the typical position. We maintain that the reason for the low percentage stems from turning a noncritical attribute, the basis shape, into a critical attribute. Only $11.4 \%$ identified the quadrilateral concave pyramid (solid 11) in the typical position. Here, too, we believe that the low percentage stems from turning a non-critical attribute, the concave shape of the basis, into a critical attribute. In both cases, the same assumption led the children to decide that the solid is not a pyramid.

We believe that the reason for relying on the prototype might be due to the children's daily acquaintance with real-world objects that resemble the solids. For example, a toilet paper roll is a familiar cylinder (solid 1), a dreidel (a toy played with by children during Hanukkah in Israel) is a triangular pyramid (solid 7) and photos of the pyramids in Passover Haggadah (a book read on Passover Eve) show square pyramids (solid 8). Conversely, children are not exposed on a daily basis to non-prototype solids.

All of the arguments given by children who correctly identified the solids were correct. Most of the arguments related to the critical attributes of those solids. Only a few related to the figure as a whole. Similar to the findings of Burger and Shaughnessy (1986), a large number of children in this study gave a visual description of the solid, for example, 'it is round', 'it looks like a toilet paper roll', 'it's like a wigwam'. The situation is different for those children who wrongly identified the solids, as they based their arguments on non-critical attributes of the solid. For instance, a mistake 
was made in identifying a hexagonal pyramid because the child did not know that a pyramid's basis can be any polygon and not necessarily a triangle: 'Because in a pyramid we have to see the triangles and here we see something else.'

Arguments based on prototypes frequently lead to a limited perception of a geometric figure. Several researchers (Hershkowitz, 1989; Schwarz \& Hershkowitz, 1999) show that children tend to view only prototypes as examples of a specific concept and hence they frequently perceive other examples that are not prototypes as non-examples.

Wilson $(1986,1990)$ attributes great importance to the use of non-examples. She claims that exposing children to non-examples of a concept that demonstrate non-critical attributes develops children's ability to distinguish between critical and non-critical attributes of concepts.

Regarding identification and naming of non-examples of solids with familiar names, the percentage of those correctly identifying the solids as non-examples is lower. This study suggests that this stems from insufficient exposure to nonexamples of this type. This is in line with the arguments relating to one, non-critical attribute of the solid, for example, 'it is somewhat like a round cylinder' (an argument referring to non-example solid 3).

When identifying solids in the different positions, the findings illustrate that many children find it difficult to identify known solids in atypical positions. A higher level of mastery was manifested with regard to familiar solids to which the children are exposed almost daily in Israel: a cylinder (solid 1) and a triangular pyramid (solid 6). This finding is supported by the claim made by Watson and Mason (2005) concerning the small number of examples presented to learners, since the learners who participated in this study were supposed to have been acquainted with those solids in kindergarten (Ministry of Education, 2010). Similarly, Tsamir et al. (2008) and Tirosh et al. (2010) stipulate that geometry teaching should include exposure to different and diverse types of examples and non-examples.

To sum up, exposure to examples of solids in different positions and non-examples of the same concepts are an important stage in building children's concept comprehension. The more learners are exposed from early childhood, starting from kindergarten, to varied examples and non-examples of solids in different positions, the more they can enhance their understanding of critical and non-critical attributes of those solids. Consequently, at every stage of teaching this discipline, it is essential and recommended that children encounter as wide a variety as possible of solids, presented in different positions.

It is recommended that further study be conducted involving a larger learner population. That study should focus on the effect of formal schooling in the subject of solids on children's enhanced ability to identify the learnt solids in different positions and on the level of justification of their arguments.

\section{Acknowledgements Competing interests}

The authors declare that they have no financial or personal relationships which may have inappropriately influenced them in writing this article.

\section{Authors' contribution}

Y.S. (Kibbutzim College of Education) was the project leader as well as conducted the interviews and collected the data. Both Y.S. and D.P. (Kibbutzim College of Education) contributed to the conception and design of the study and both wrote and edited the final version of the manuscript.

\section{References}

Burger, W.F., \& Shaughnessy, J.M. (1986). Characterizing the Van Hiele levels of development in geometry. Journal for Research in Mathematics Education, 17(1) 31-48. http://dx.doi.org/10.2307/749317

Clements, D.H., \& Sarama, J. (2000). Young Children's ideas about geometric shapes. Teaching Children Mathematics, 6(8), 482-488. Available from http://www.jstor. org/stable/41197461

Cohen, M., \& Carpenter, J. (1980). The effects of non-examples in geometrical concept acquisition. International Journal of Mathematical Education in Science and Technology, 11(2), 259-263. http://dx.doi.org/10.1080/0020739800110218

Crowley, M.L. (1987). Van Hiele model of the development of geometric thought. In M.M. Lindquist, \& A.P. Shulte (Eds.), Learning and Teaching Geometry, K-12, 1987 Yearbook of the National Council of Teachers of Mathematics (pp. 1-16). Reston, VA: NCTM.

Guberman, R. (2008). A framework for characterizing the development of arithmetic thinking. In D. de Bock, B.D. Søndergaard, B.G. Alfonso, \& C.C.L. Cheng (Eds.) Proceedings of ICME-11-Topic study group 10: Research and development in the teaching and learning of number systems and arithmetic (pp. 113-121). Monterrey, Mexico. Available from http://tsg.icme11.org/document/get/879

Gutiérrez, A. (1992). Exploring the links between Van Hiele levels and 3-dimensional geometry. Structural Topology, 18, 31-47. Available from http://www.iri.upc.edu/ people/ros/StructuralTopology/ST18/st18-07-a3-ocr.pdf

Hershkowitz, R. (1989). Visualisation in geometry - two sides of the coin. Focus on Learning Problems in Mathematics, 11(1), 61-76. http://dx.doi.org/10.1017/ CBO9781139013499.006

Hershkowitz, R. (1990). Psychological aspects of learning geometry. In P. Nesher, \& J. Kilpatrick (Eds.), Mathematics and cognition (pp. 70-95). Cambridge: Cambridge University Press. http://dx.doi.org/10.1017/CBO9781139013499.006

Hershkowitz, R. (1992). Cognitive aspects in geometry teaching and learning - Part II. Aleh Mathematics Teacher Brochure, 10, 20-27. [Hebrew]

Hershkowitz, R., \& Vinner, S. (1983). The role of critical and non-critical attributes in the concept image of geometrical concepts. In R. Hershkowitz (Ed.), Proceeding of the Seventh Conference of the International Group for the Psychology of Mathematics (pp. 223-228). Rehovot, Israel: Weizmann Institute of Science.

Klausmeier, H., \& Feldman, K. (1975). Effects of a definition and a varying number of examples and non-examples on concept attainment. Journal of Educationa Psychology, 67, 174-178. http://dx.doi.org/10.1037/h0076998

Koester, B.A. (2003). Prisms and pyramids: Constructing three-dimensional models to build understanding. Teaching Children Mathematics, 9(8), 436-442. Available from http://www.jstor.org/stable/41198209

McKinney, C., Larkins, A., Ford, M., \& Davis III, J. (1983). The effectiveness of three methods of teaching social studies concepts to fourth-grade students: An aptitude-treatment interaction study. American Educational Research Journal, 20, 663-670. http://dx.doi.org/10.3102/00028312020004663

Ministry of Education. (2006). Mathematics curriculum for the 1st-6th grades in all the sectors. Jerusalem: Curricula Department, Ministry of Education, Culture and Sport. [Hebrew]

Ministry of Education. (2010). Mathematics curriculum for kindergarten in the state and state-religious education frameworks. Jerusalem: Curricula Department, Ministry of Education, Culture and Sport. [Hebrew]

National Council of Teachers of Mathematics. (2000). Principles and standards for school mathematics. Reston, VA: NCTM.

Patkin, D. (2010). The role of "personal knowledge" in solid geometry among primary school mathematics teachers. Journal of the Korean Society of Mathematical Education. Series D: Research in Mathematical Education, 14(3), 263-279.

Patkin, D., \& Sarfaty, Y. (2012). The effect of solid geometry activities of pre-service elementary school mathematics teachers on concepts understanding and mastery of geometric thinking levels. Journal of the Korean Society of Mathematical Education. Series D: Research in Mathematical Education, 16(1), 31-50. 
Petty, O., \& Jansson, L. (1987). Sequencing examples and non-examples to facilitate concept attainment. Journal for Research in Mathematics Education, 18(2), 112125. http://dx.doi.org/10.2307/749246

Schwarz, B., \& Hershkowitz, R. (1999). Prototypes: Brakes or levers in learning the function concept? Journal for Research in Mathematics Education, 30, 362-389. http://dx.doi.org/10.2307/749706

Tall, D., \& Vinner, S. (1981). Concept images and concept definition in mathematics with particular reference to limits and continuity. Educational Studies in Mathematics, 12, 151-169. http://dx.doi.org/10.1007/BF00305619

Tirosh, D., Tsamir, P., \& Levenson, E. (2010). Triangle - yes or no? Intuitions and triangles in kindergartens. Literacy and Language, 3, 161-175. [Hebrew]

Tirosh, D., Tsamir, P., Levenson, E., Tabach, M., \& Barkai, R. (2011). Prospective and practicing knowledge preschool teachers' mathematics knowledge and selfefficacy: Identifying two and three dimensional figures. In B. Roesken, \& M. Casper (Eds.), Current State of Research on Mathematical Beliefs XVII. Proceedings of the 17th MAVI (Mathematical Views) Conference (pp. 221-230). Bochum, Germany: Ruhr-Universität. Available from http://www.ruhr-uni-bochum.de/imperia/md/ content/mathematik/Roesken/mavi17_final_content.pdf
Tsamir, P., Tirosh, D., \& Levenson, E. (2008). Intuitive nonexamples: The case of triangles. Educational Studies in Mathematics, 69(2), 81-95. http://dx.doi. org/10.1007/s10649-008-9133-5

Van Hiele, P.M. (1997). Structuure. Zutphen, Netherlands: Uitgeverrj Thieme.

Van Hiele, P.M. (1999). Developing geometric thinking through activities that begin with play. Teaching Children Mathematics, 5(6), 310-316. Available from http:// www.jstor.org/stable/41198852

Vinner, S. (1991). The role of definitions in the teaching and learning of mathematics. In D. Tall (Ed.), Advanced mathematical thinking (pp. 65-81). Dordrecht: Kluwer.

Vinner, S., \& Hershkowitz, R. (1983). On concept formation in geometry. ZDM: The International Journal on Mathematics Education, 15, 20-25.

Watson, A., \& Mason, J. (2005). Mathematics as a constructive activity: Learners generating examples. Mahwah, NJ: Lawrence Erlbaum Associates.

Wilson, S. (1986). Feature frequency and the use of negative instances in a geometric task. Journal for Research in Mathematics Education, 17(2), 130-139. http:// dx.doi.org/10.2307/749258

Wilson, S. (1990). Inconsistent ideas related to definitions and examples. Focus on Learning Problems in Mathematics, 12, 31-47. 


\section{Appendix 1}

Photos of the physical solids

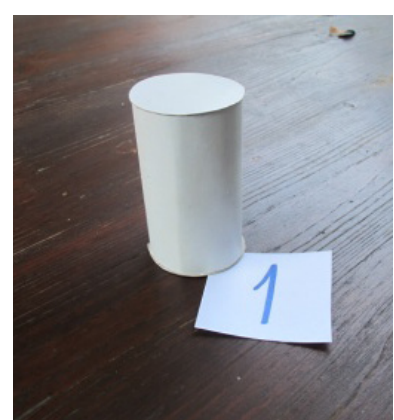

Position A

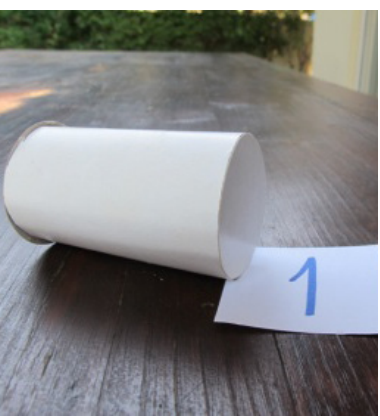

Position A

Solid 1

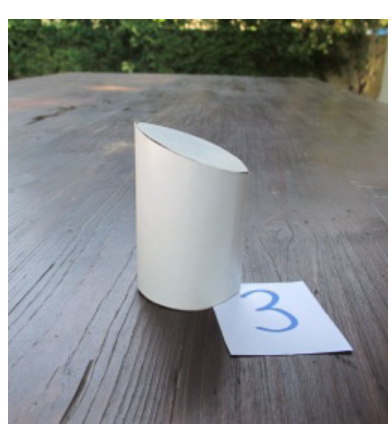

Position A

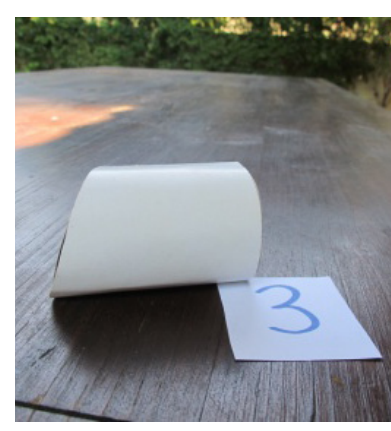

Position A

Solid 3

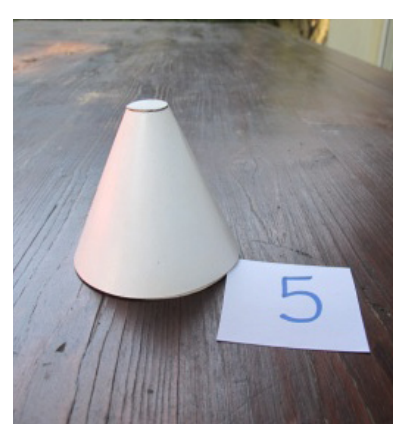

Position A

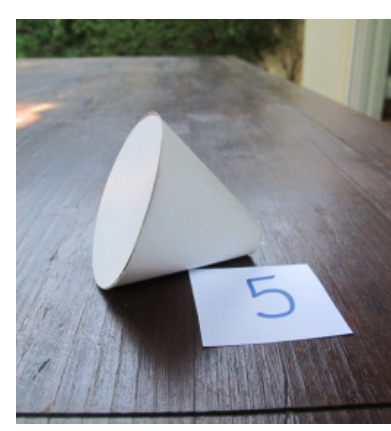

Position A

Solid 5

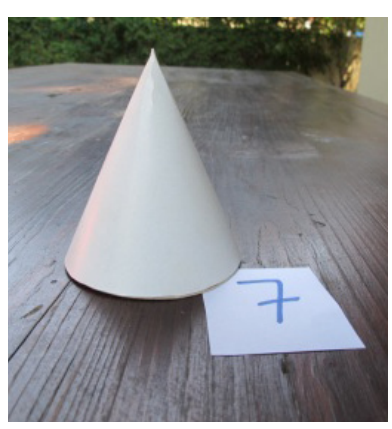

Position A

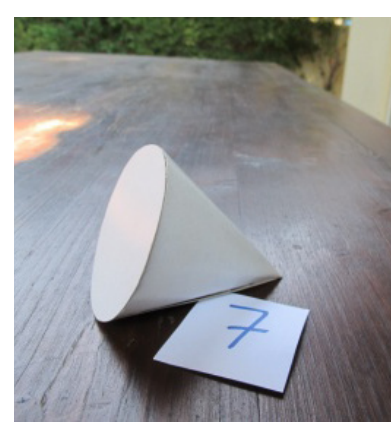

Position A
Solid7

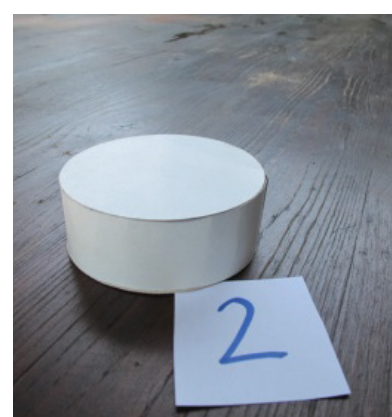

Position A

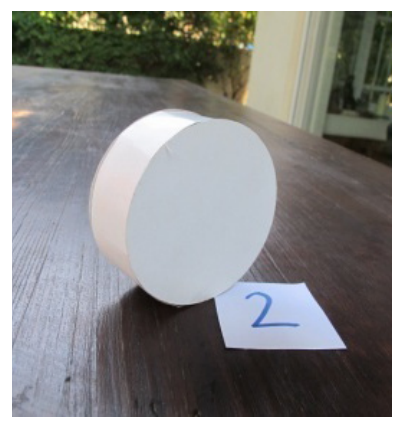

Position A

Solid 2

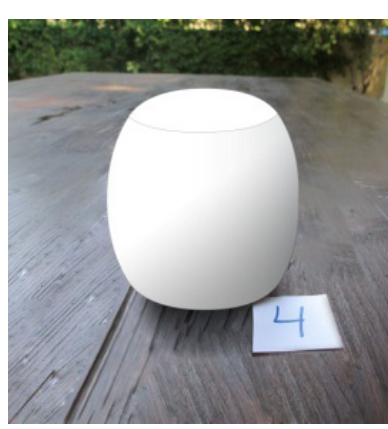

Position A

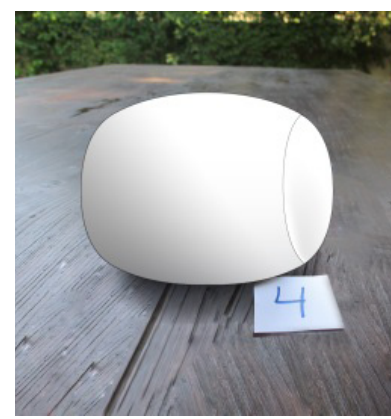

Position A

Solid 4

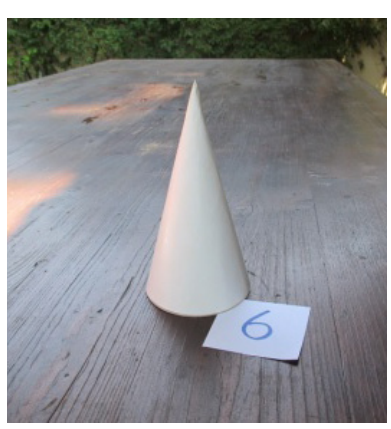

Position A

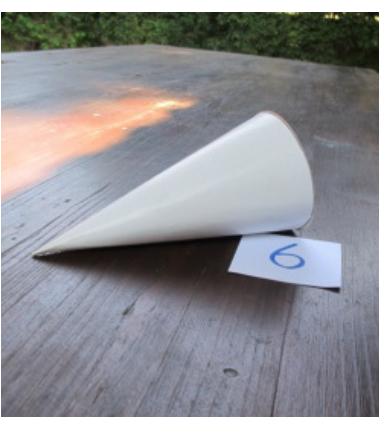

Position A

Solid 6

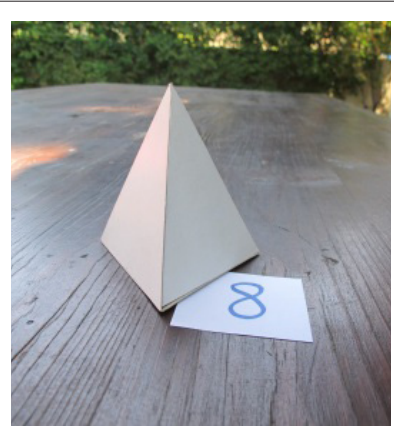

Position A
Position A

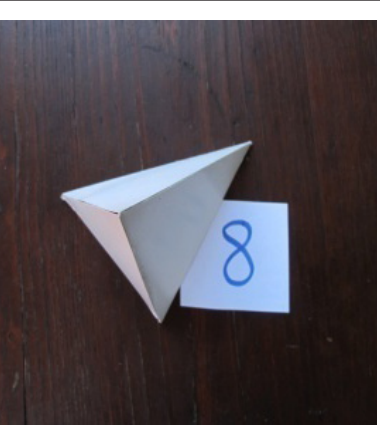

Solid 8 


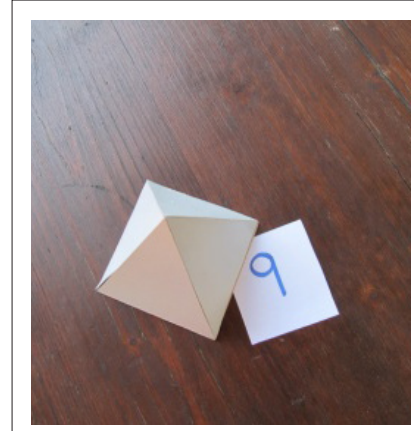

Position A

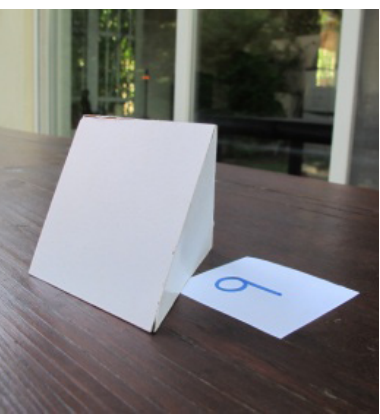

Position A Solid 9

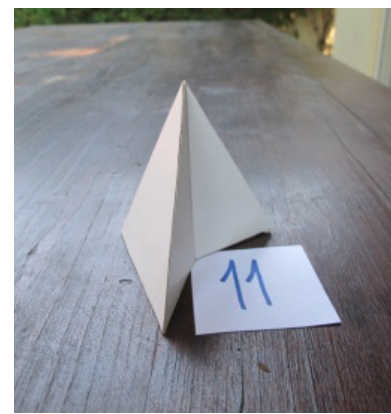

Position A

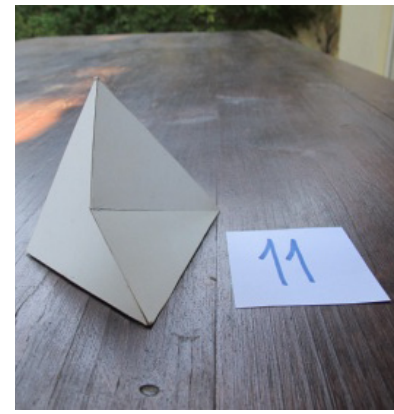

Position A

Solid 11

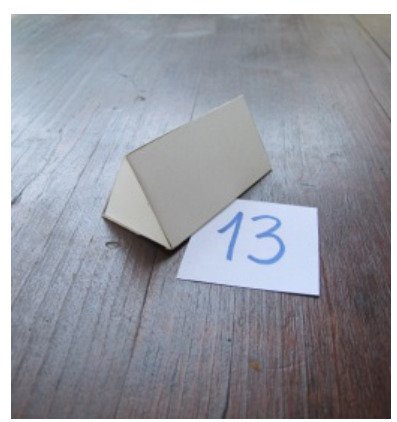

Position A

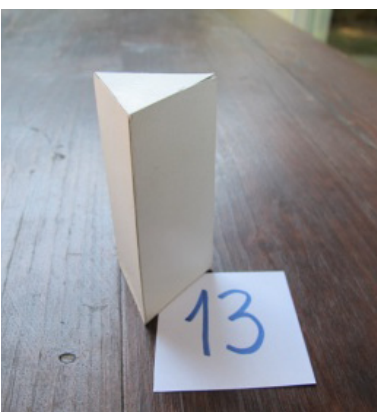

Position A

Solid 13
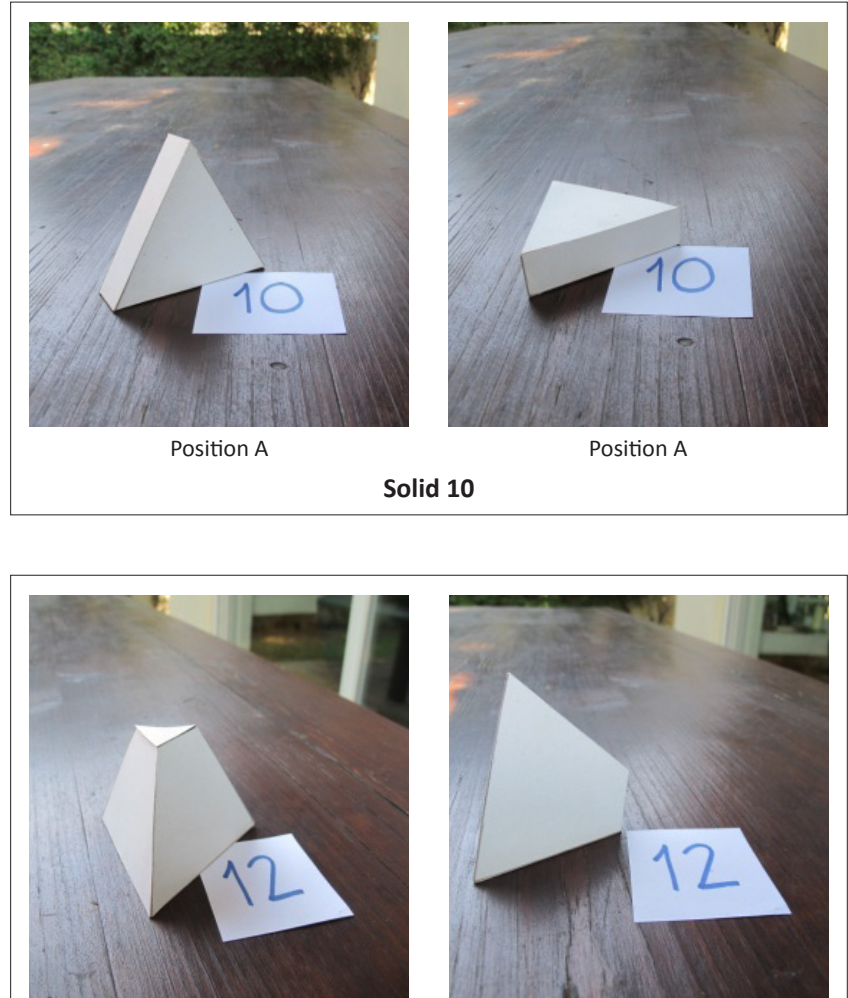

Position A

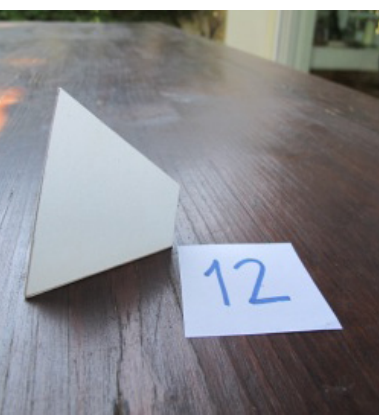

Position A

Solid 12

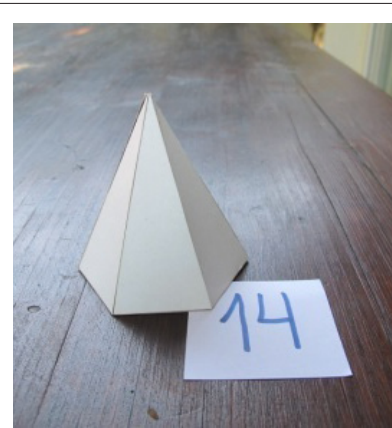

Position A

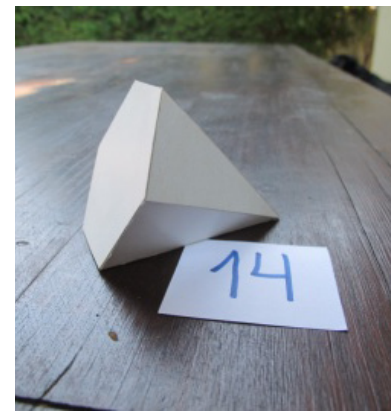

Position A
Solid 14 